\title{
NUMERICAL STUDY OF NATURAL GAS COMBUSTION IN A PUSHER FURNACE
}

\section{Nomenclature:}

$\alpha, \beta-$ constants dependent on the properties of the interface between the modeled region and its surroundings,

$C$ - radiation diffusion term computed from local concentration of $\mathrm{H}_{2} \mathrm{O}$ and $\mathrm{CO}_{2}$,

$D_{i, m}$ - laminar diffusion,

$e$ - gas energy per unit mass,

$\vec{g}-$ external force acting on the fluid, the gravity,

$S c_{t}-$ turbulent Schmidt number, $S c_{t}=0.7$,

$u_{i}$ - gas velocity components,

$Y_{i}-$ mass fraction of the $i$-th component.

Greek Letters:

$\kappa$ - Poisson constant,

$\mu_{e f f}-$ effective friction coefficient,

$\rho$ - flue gas mass density.

\section{INTRODUCTION}

One of the most important problems in hot-rolling process is gas pollutants emission into the atmosphere, especially carbon oxides $\left(\mathrm{CO}\right.$ and $\left.\mathrm{CO}_{2}\right)$, nitrogen oxides $\left(\mathrm{NO}_{\mathrm{x}}\right)$ and aliphatic hydrocarbons. The main source of gas pollutants from hot-rolling mill are the heating and heat treatment charge furnaces. They are equipped with the gas-fired burners.

* Ph.D., ** Ph.D., D.Sc.: AGH University of Science and Technology, Faculty of Metals Engineering and Industrial Computer Science, Krakow, Poland; e-mail: straka@metal.agh.edu.pl 
By application of natural gas with high concentration of methane, low-emission burners and recuperators for heat recovery from exhaust gases the reduction of $\mathrm{NO}_{\mathrm{x}}$ appears at the beginning of the process. In spite of many advantages of natural gas, it is also a source of nitrogen oxides generated during combustion.

Nitrogen oxides $\left(\mathrm{NO}_{\mathrm{x}}\right)$ are one of the most harmful substances for environment resulting from the combustion of fuels, that is why researches study how to reduce $\mathrm{NO}_{\mathrm{x}}$ emission. Typical combustion gases contain two kinds of oxides: $\mathrm{NO}$ and $\mathrm{NO}_{2}$ (the volumetric share of $\mathrm{NO}$ amounts to about $95 \%$ or even more, the rest being $\mathrm{NO}_{2}$ ). Other kinds of nitrogen oxides are $\mathrm{N}_{2} \mathrm{O}, \mathrm{N}_{2} \mathrm{O}_{3}$ and $\mathrm{N}_{2} \mathrm{O}_{5}$, but they do not play any essential role [1] $\mathrm{NO}_{2}$ is also a greenhouse gas and one of the California type smog gases. In the presence of stream water and in the case of atmospheric discharges $\mathrm{NO}_{2}$ forms nitric acid. $\mathrm{NO}$ is not considered to be so toxic as $\mathrm{NO}_{2}$. However $\mathrm{NO}$ is the main source of $\mathrm{NO}_{2}$ emitted into the atmosphere. This requires the knowledge of the mechanisms of the formation and reduction of $\mathrm{NO}_{\mathrm{x}}$ emissions on the basis of the kinetics of chemical reactions. There are four different mechanisms of the formation of NO: the thermal, prompt, fuel mechanism and by means of $\mathrm{N}_{2} \mathrm{O}$.

The thermal mechanism of NO was described by Zeldovich [2]. These are the reactions of oxidizing the nitrogen taken from the air at temperature exceeding $1400{ }^{\circ} \mathrm{C}$. The prompt mechanism of Fenimore [3] concerns the combustion of rich mixture of hydrocarbons and air. Prompt NO is formed rapidly in the course of the combustion, immediately before the front or just in the front of the flame. In industry the role of prompt NO is no significant. The fuel NO is formed from fuel nitrogen in the front of the flame and its amount increases with the growing concentration of oxygen. The concentration of fuel NO in the global emission of nitrogen oxides grows with the decrease of the heat release of the combustion chamber $[2,4,5] . \mathrm{NO}_{\mathrm{x}}$ reduction is important subject of experimental and numerical studies [6-8].

The heating furnace is designed for heating charge. The furnace is designed taking into account the character and production technology requirements. The production technology determines the procedure of heating charge, its temperature profiles, the composition of furnace atmosphere and other parameters. Most of the furnaces are automatically operated and the loading of the charge is made by minimum opening charge door. These methods influence the optimization of gas consumption, air excess and heat losses limitation. The experiments on a real device are expensive and difficult to be done, in extreme cases even hazardous, therefore an alternative way to test the behavior of the furnace is mathematical modeling. The main motivation of the combustion model is the optimization of the production of the nitrogen oxide, which strongly depends on the temperature and thus can be controlled by intelligent distribution of fuel and oxygen to burners.

\section{MATHEMATICALMODEL}

The mathematical model of combustion is based on the Navier-Stokes equations for a mixture of multiple components. Currently, the following components of the mixture are considered: chemical compounds engaged in major thermal and fuel $\mathrm{NO}$ reactions (nitrogen $\left(\mathrm{N}_{2}\right)$, oxygen $\left(\mathrm{O}_{2}\right)$, nitric oxide $(\mathrm{NO})$, methane $\left(\mathrm{CH}_{4}\right)$, carbon dioxide $\left(\mathrm{CO}_{2}\right)$ and vapor $\left.\left(\mathrm{H}_{2} \mathrm{O}\right)\right)$. 
The gas phase is described by the set of equations given below. As stated above, the mass balance is governed by equations defined for each sub-component (the Einstein summation is used):

$$
\frac{\partial}{\partial t}\left(\rho Y_{i}\right)+\frac{\partial}{\partial x_{j}}\left(\rho Y_{i} u_{j}\right)=\nabla \vec{J}_{i}+R_{i}
$$

where $\rho$ is the flue gas mass density, $Y_{i}$ mass fraction of the $i$-th component, and $u_{j}$ are the gas velocity components. The right-hand side terms describe the laminar and turbulent diffusion of the components and either production or consumption due to chemical reactions within the $R_{i}$ term.

The equations of component mass balance are accompanied by the equation of total mass balance:

$$
\frac{\partial \rho}{\partial t}+\frac{\partial\left(\rho u_{j}\right)}{\partial x_{j}}=0
$$

Equations of momentum conservation are as follows:

$$
\frac{\partial}{\partial t}\left(\rho u_{i}\right)+\frac{\partial\left(\rho u_{i} u_{j}\right)}{\partial x_{j}}=\frac{\partial p}{\partial x_{i}}+\frac{\partial}{\partial x_{j}}\left[\mu_{e f f}\left(\frac{\partial u_{i}}{\partial x_{j}}+\frac{\partial u_{j}}{\partial x_{i}}-\frac{2}{3} \delta_{i j} \frac{\partial u_{l}}{\partial x_{l}}\right)\right]+g_{i}
$$

where $\vec{g}=\left[g_{1}, g_{2}, g_{3}\right]$ is the external force acting on the fluid, in our case the gravity. The effective viscosity coefficient $\mu_{\text {eff }}$ is calculated from the turbulence model.

The last equation describes the conservation of energy:

$$
\frac{\partial}{\partial t}(\rho h)+\frac{\partial\left(\rho u_{j} h\right)}{\partial x_{j}}=-\frac{d Y_{\mathrm{CH}_{4}}}{d t} h_{\mathrm{CH}_{4}}+q_{r t c}+q_{s}
$$

where the right-hand side terms are the heat of combustion, heat transfer by radiation and conduction, and heat source or sink. The heat transfer terms are computed as follows:

$$
q_{r t c}=\operatorname{div}\left(\left(\lambda+C T^{3}\right) \operatorname{grad} T\right)
$$

The radiation heat transfer is fully described by an integral-differential equation of radiation, which is computationally expensive to solve. However, as the flue gas can be considered an optically thick matter, the above approximation of the radiation flux called the Rosseland radiation model can be applied. The term $C$ in Eq. (5) is radiation diffusion term computed from local concentration of $\mathrm{H}_{2} \mathrm{O}$ and $\mathrm{CO}_{2}$. 
The heat sink term is nonzero only in the edge computation cells and describes the heat transfer with the walls of the furnace via conduction and radiation:

$$
q_{s}=\alpha\left(T-T_{\text {wall }}\right)-\beta\left(T^{4}-T_{\text {wall }}^{4}\right)
$$

where $\alpha$ and $\beta$ are constants dependent on the properties of the interface between the modeled region and its surroundings.

Mass change rate of $\mathrm{CH}_{4}$ is described by Eddy Dissipation Model (EDM):

$$
\frac{d Y_{\mathrm{CH}_{4}}}{d t}=\min \left[M_{\mathrm{CH}_{4}} \rho \frac{\varepsilon}{k} A \min \left(\frac{Y_{\mathrm{CH}_{4}}}{M_{\mathrm{CH}_{4}}}, B \frac{Y_{\mathrm{O}_{2}}}{M_{\mathrm{O}_{2}}}\right), M_{\mathrm{CH}_{4}} \rho \frac{\varepsilon}{k} A B \frac{Y_{\mathrm{CO}_{2}}+Y_{\mathrm{H}_{2} \mathrm{O}}}{M_{\mathrm{CO}_{2}}+2 M_{\mathrm{H}_{2} \mathrm{O}}}\right]
$$

where $A=4$ and $B=0.5$.

These equations are accompanied by the equation of state:

$$
p=(\kappa-1) \rho\left(e-\frac{1}{2}\left(u_{i} u_{i}\right)^{\frac{1}{2}}\right)
$$

where $\kappa$ is the Poisson constant and $e$ is the gas energy per unit mass.

For the turbulence modeling, we use the standard $k-\varepsilon$ model, which describes the evolution of turbulence using two equations, first one for the turbulent kinetic energy:

$$
\frac{\partial}{\partial t}(\rho k)+\frac{\partial\left(\rho u_{j} k\right)}{\partial x_{j}}=\frac{\partial}{\partial x_{j}}\left[\left(\mu+\frac{\mu_{t}}{\sigma_{k}}\right) \frac{\partial k}{\partial x_{j}}\right]+G_{k}-\rho \varepsilon
$$

And the second for the turbulent kinetic energy dissipation rate:

$$
\frac{\partial}{\partial t}(\rho \varepsilon)+\frac{\partial\left(\rho u_{j} \varepsilon\right)}{\partial x_{j}}=\frac{\partial}{\partial x_{j}}\left[\left(\mu+\frac{\mu_{t}}{\sigma_{\varepsilon}}\right) \frac{\partial \varepsilon}{\partial x_{j}}\right]+C_{1 \varepsilon} \frac{\varepsilon}{k} G_{k}-C_{2 \varepsilon} \rho \frac{\varepsilon^{2}}{k}
$$

Constants in this model have to be determined empirically, we use the following values:

$$
C_{1 \varepsilon}=1.44, C_{2 \varepsilon}=1.92, \sigma_{k}=1.0, \sigma_{\varepsilon}=1.3 \text {. }
$$

The term $G_{k}$ describes the production of turbulence, can be derived from the Reynolds averaging process and written in the terms of the fluctuating part of the velocity as:

$$
G_{k}=\tau_{j l} \frac{\partial u_{j}}{\partial x_{l}}=\overline{\rho u_{j}^{\prime} u_{l}^{\prime}} \frac{\partial u_{j}}{\partial x_{l}}=\mu_{t} S^{2}, \quad \text { with } \quad S_{i j}=\frac{1}{2}\left(\frac{\partial u_{i}}{\partial x_{j}}+\frac{\partial u_{j}}{\partial x_{i}}\right)
$$


where $\tau_{j l}$ is the Reynolds stress tensor and $S_{i j}$ is mean strain rate. During computation, fluctuations $u_{j}^{\prime}$ and $u_{l}^{\prime}$ are unknown, we use the Boussinesq hypothesis that the Reynolds stresses are proportional to the mean strain rate.

Left hand sides of the equations describe passive advection of the respective quantities by the advection velocity $u$. Right hand sides describe their spatial diffusion, production and destruction.

Diffusion of the species consists of two processes, laminar and turbulent, and the diffusion term in Eq. (1) can be written in the form:

$$
\vec{J}_{i}=-\left(\rho D_{i, m}+\frac{\mu_{t}}{S c_{t}}\right) \nabla Y_{i}
$$

First term corresponds to linear laminar diffusion, the second one to turbulent diffusion. Considering the fact that the turbulent diffusion generally predominate the laminar one, and the term $D_{i, m}$ is difficult to determine, the laminar diffusion can be usually neglected. The term $S c_{t}$ is the turbulent Schmidt number and we put $S c_{t}=0.7$.

For numerical solution of the equations, finite volume method is used [9]. For left and right hand sides in Eqs. (1)-(4) advection upstream splitting method [10] is used to approximate fluxes in the FVM formulation, and edge dual-volume approximation is used to approximate the second order derivatives respectively. Detailed description of the solution procedure is presented in [11].

This model of NO production has been developed to approximate quantitative description of NO emissions leaving a gas combustion chamber. The real mechanism of flue gas production is complex, so that just the most important phenomena and reaction paths were considered. There are two major processes attributing to the total NO. The former is known as thermal NO or Zeldovich NO and simply consists of oxidation of atmospheric nitrogen at high temperature. The latter is called Fuel NO and describes NO creation from nitrogen, which is chemically bounded in fuel. Thermal NO generation mechanism attributes only at high temperature and is represented by a set of three equations, introduced by Zeldovich and extended by Bowman [5, 12-14]. These are the reactions of oxidizing the nitrogen taken from the air at temperature exceeding $1400{ }^{\circ} \mathrm{C}$ :

$$
\begin{aligned}
& \mathrm{O}+\mathrm{N}_{2} \stackrel{k_{1}}{\longrightarrow} \mathrm{NO}+\mathrm{N} \\
& \mathrm{N}+\mathrm{O}_{2} \stackrel{k_{2}}{\longrightarrow} \mathrm{NO}+\mathrm{O} \\
& \mathrm{N}+\mathrm{OH} \stackrel{k_{3}}{\longrightarrow} \mathrm{NO}+\mathrm{H}
\end{aligned}
$$

The rate of NO formation can be expressed by the equation:

$$
\frac{d[\mathrm{NO}]}{d t}=k_{1}[\mathrm{O}]\left[\mathrm{N}_{2}\right]+k_{2}[\mathrm{~N}]\left[\mathrm{O}_{2}\right]+k_{3}[\mathrm{~N}][\mathrm{OH}]
$$


The atomic nitrogen is formed during reaction (13) and it is used in the reactions (14) and (15). The rate of the generation of atoms in compliance with the theory of stationary state is expressed by equation:

$$
\frac{d[\mathrm{~N}]}{d t}=k_{1}[\mathrm{O}]\left[\mathrm{N}_{2}\right]-k_{2}[\mathrm{~N}]\left[\mathrm{O}_{2}\right]-k_{3}[\mathrm{~N}][\mathrm{OH}]
$$

As the reaction (14) is fast in comparison with the reaction (13), we assume that the concentration of nitrogen attains a quasi-equilibrium state.

Then:

$$
\frac{d[\mathrm{~N}]}{d t}=0
$$

and the equation takes the form:

$$
\frac{d[\mathrm{NO}]}{d t}=2 k_{1}[\mathrm{O}]\left[\mathrm{N}_{2}\right]
$$

where: $k_{1}, k_{2}$ and $k_{3}$ are coefficients of the reaction rates of (13), (14) and (15).

\section{DATA PROCESSING AND DISCUSSION OF RESULTS}

The modeling of hot-rolling process requires many fields of knowledge e.g.: combustion chemistry of natural gas or technology of the process, which should be included in the presented model. The formulation of boundary conditions of the calculated process is the primary step of numerical simulation (Fig. 1).

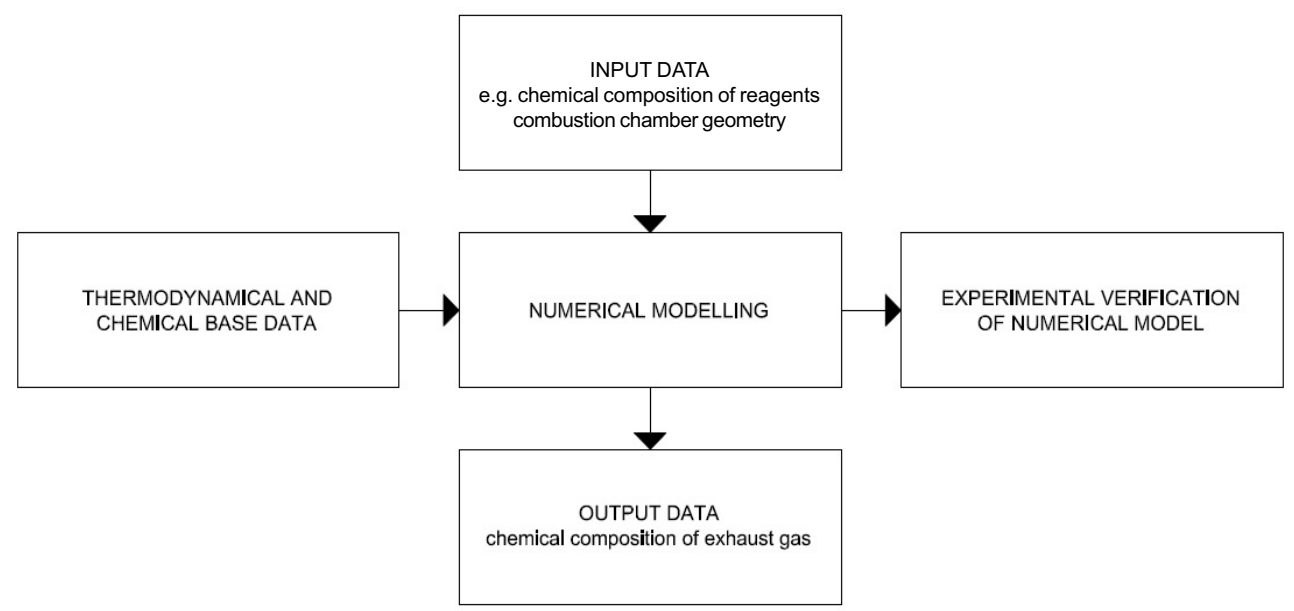

Fig. 1. Scheme of numerical simulation procedure 
The numerical model is based on various parameters used in simulation including e.g.:

- type of furnace and its geometry,

- furnace zoning, type and number of burners,

- excess air ratio for burners,

- air and gas volume flow,

- gas and air composition,

- pressure,

- temperature in particular zones of furnace.

The mathematical and numerical model has been done for real working heating furnace used in hot-rolling mill in Poland. The model is based on the pusher furnace with flat roof, whose width is $7.8 \mathrm{~m}$ and length is $28 \mathrm{~m}$. The combustion chamber of the heating furnace consists of 4 zones, its geometry is described in Figure 2. The flat flame burners (type PWG 400, PWG 630) mounted in the roof of the furnace are applied. The pusher furnaces are adapted for slab heating to hot working temperature. The numerical simulation has been done for heating furnaces without charge.

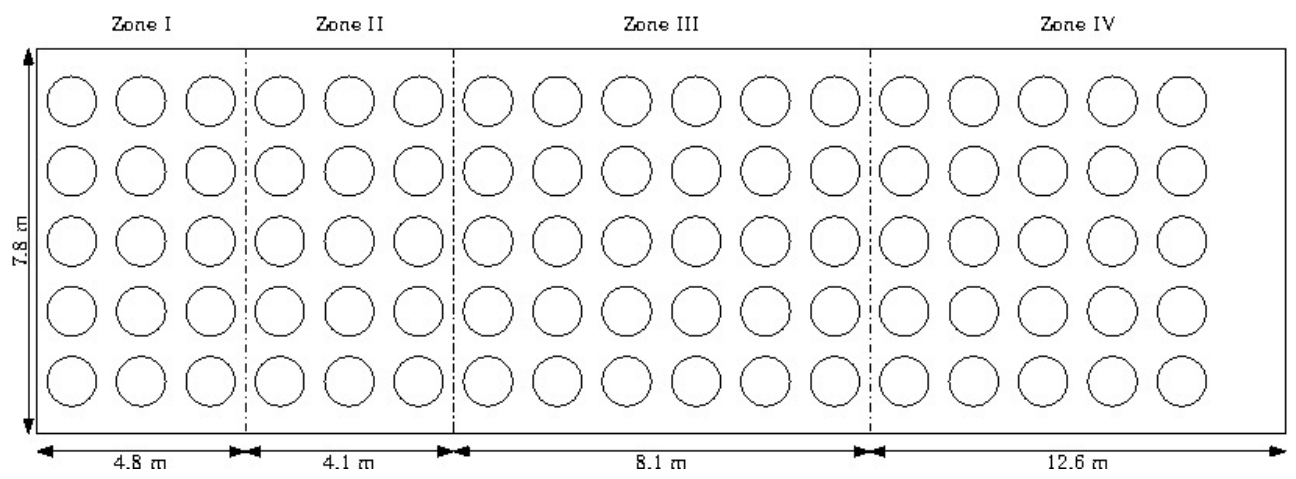

Fig. 2. Zoning of the furnace

The furnace is fired by natural gas with high concentration of methane. The natural gas composition is $\mathrm{CH}_{4}=95.5 \%, \mathrm{CO}_{2}=0.2 \%, \mathrm{O}_{2}=0.1 \%, \mathrm{~N}_{2}=4.2 \%$. The air composition is $\mathrm{O}_{2}=21 \%, \mathrm{~N}_{2}=79 \%$. The parameters of gas and air volume flow for particular zones of the furnace used in simulation are presented in Table 1 . Table 2 includes gas and air flow supplied to burners in particular zones of the furnace.

Table 1. Gas and air volume flow, temperature for the combustion chamber zones

\begin{tabular}{||l|c|c|c|c||}
\hline Parameters & I & II & III & IV \\
\hline Gas volume flow $\left[\mathrm{m}^{3} / \mathrm{h}\right]$ & 237.03 & 130.39 & 701.89 & 473.79 \\
\hline Air volume flow $\left[\mathrm{m}^{3} / \mathrm{h}\right]$ & 2150.62 & 1553.07 & 6802.90 & 4801.48 \\
\hline
\end{tabular}


Table 2. Gas and air volume flow for burners

\begin{tabular}{||l|c|c|c|c||}
\hline \hline Parameters & I & II & III & IV \\
\hline Number & 15 & 15 & 30 & 25 \\
\hline Gas volume flow $\left[\mathrm{m}^{3} / \mathrm{h}\right]$ & 0.0029 & 0.0024 & 0.0065 & 0.0053 \\
\hline Air volume flow $\left[\mathrm{m}^{3} / \mathrm{h}\right]$ & 0.0260 & 0.0288 & 0.0630 & 0.0534 \\
\hline
\end{tabular}

Defined boundary conditions and initial value of certain parameters are very important for the numerical simulations. The parameters, being boundary conditions e.g.: temperature and exhaust gases velocity, correspond to real condition of the furnace. The calculations have been done without the presence of the charge in the process as the first step of modeling such complex technological process. Presented results are preliminary calculations. Next, the model will be extended taking into account the heat exchange between the charge and walls in the atmosphere of the furnace. The calculations considering the charge in the furnace will allow comparison of the numerical results and experimental data.

The structure of calculate network is orthogonal with constant step $\Delta x$ and $\Delta y$, corresponding to geometrical shape of combustion chamber with burners inside. The charge is not included in calculate network. For numerical calculations the boundary condition on the place of the burners was defined as velocity of gas medium (methane - air mixture) with determined composition and temperature. The methane-air mixture density was calculated by means of ideal gas law. The parameters of exhaust gases e.g.: viscosity coefficient, specific heat and heat conduction were calculated by NASA polynomials. It is a $2 \mathrm{D}$ geometric model. The model was developed taking into account the balance between the computation complexity and the precision of the simulation. The simplified chemistry of reaction kinetics has been used for the production of NO and simple kinetics of the methane oxidation. The numerical results are presented for four zones of combustion chamber. Figures present temperature, velocity and composition of exhaust gases (Figs 3-6).

The highest velocities appear close to the charge door (where the exhaust gases outlet is situated) decreasing in the direction to the exit of the pusher furnace (Fig. 3). Maximum velocity is caused by decreasing of pressure. In the charge door, the exhaust gases are decompressed. Temperature field is presented in Figure 4. Temperature calculations were carried out for empty furnace chamber (no charge inside), so temperature is higher than might be expected (c.a. $1823 \mathrm{~K}$ ). It can be explained by neglecting heat transfer to the charge. The highest temperature was in III and IV zones, where high gas flow was obtained.

High temperature causes the generation of nitrogen oxides (NO) (Fig. 5). The only source of NO in the natural gas combustion is the thermal NO mechanism. The computed amount of NO is c.a. 264 ppm. NO concentration is evidently high, but is caused by high temperature. Unfortunately, temperature is one of the most important parameters in hot-rolling process. Temperature of the furnace depends strongly on technological requirements and can not be decreased in respect of quality of steel production. 


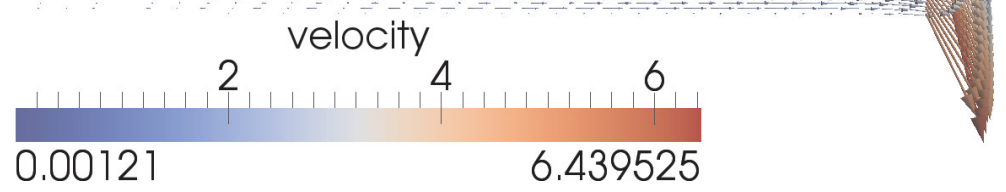

Fig. 3. Velocity field of exhaust gas $[\mathrm{m} / \mathrm{s}]$

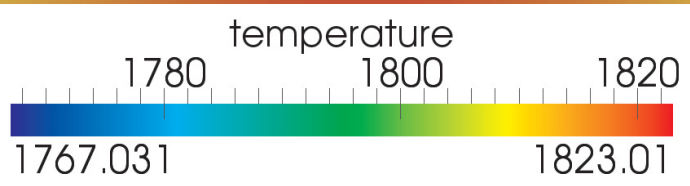

Fig. 4. Temperature field of exhaust gas [K]

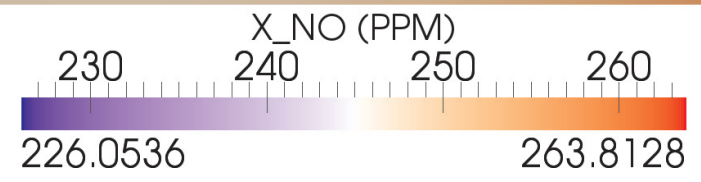

Fig. 5. Profiles of NO molar fractions, ppm

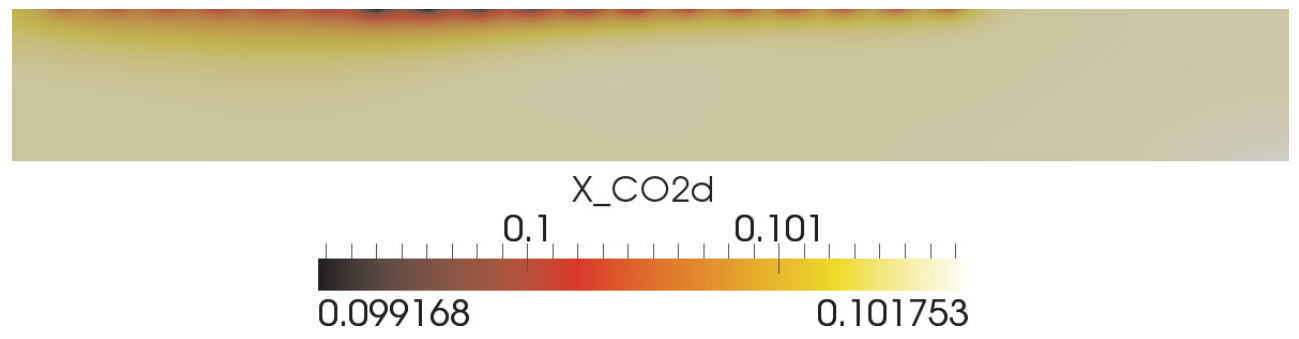

Fig. 6. Profiles of $\mathrm{CO}_{2}$ mole fractions 
The concentration of $\mathrm{CO}_{2}$ is presented in Figure 6. The computed molar fraction of $\mathrm{CO}_{2}$ is the highest close to charge door and seems to be adequate compared to real conditions of the combustion process in the pusher furnace. The highest concentration of $\mathrm{CO}_{2}$ is in the front of the flame.

\section{CONCLUSIONS}

A numerical model of gas combustion in the pusher furnace has been developed. The model was developed taking into account the balance between the computation complexity and the precision of the simulation. This was also the reason why simplified reaction kinetics has been used instead of full reaction set for the production of NO and simple kinetic approach of the methane oxidation. Presented results with emphasis on the NO production are not adequate in comparison with real life devices, because the charge was not included. Although, it is preliminary model to estimate the atmosphere of pusher furnace. Still there are places where enhancing of the model is needed, mainly the radiation heat transfer modeling and chemistry of methane combustion process including NO chemistry.

\section{Acknowledgement}

This work was supported by the Polish Ministry of Science and Higher Education (N R07 002204$)$.

\section{REFERENCES}

[1] Wilk R.: Low-emission combustion, Wyd. Politechniki Śląskiej, Gliwice, 2002

[2] Zeldovich J.B.: Acta Physicochimica USSR, 21 (1946) 577-628

[3] Fenimore C.P.: Formation of nitric oxide in premixed hydrocarbon flames, 13th Symposium (International) on Combustion, University of Utah Salt Lake City, Utah, 23.-29., August 1970, Pittsburgh, The Combustion Institute, 1971, 373-380

[4] Tomeczek J., Gradoń B.: Combusion Science and Technology, 125 (1997), 159-180

[5] Miller J.A., Bowman C.T.: Progress in Energy and Combustion Science, 15 (1989), 287-338

[6] Xu H., Smoot D., Hill S.C.: Energy Fuels, 13 (1999), 411-420

[7] Dagaut P., Dayma G.: Journal of Physical Chemistry, 110 (2006), 6608-6616

[8] Le Cong T., Daguat P.: Energy Fuels, 23 (2009), 725-734

[9] Makovička J., Havlena V., Beněs M.: Mathematical modelling of steam and flue gas flow in a heat exchanger of a steam boiler, Algoritmy 2002, Podbánské, Slovakia, 8.-13. September 2002, Bratislava, Publishing House of STU, 2002, 171-178

[10] Liou M.S., Steffen Jr. C.: Journal of Computational Physics, 107 (1993), 23-29

[11] Straka R., Makovička J.: Kybernetika, 43 (2007), 879-891

[12] Westbrook C.K., Dryer F.L.: Chemical kinetics and modeling of combustion processes, Eighteenth Symposium (International) on Combustion, University of Waterloo, Waterloo, Canada, 17.-22. August 1980, Pittsburgh, The Combustion Institute, 1981, 749-767 
[13] Baulch D.L., Cobos C.J., Cox R.A., Frank P., Hayman G., Just T.H., Kerr J.A., Murrells T., Pilling M.J., Troe J., Walkner R.W., Warnatz J.: Combustion and Flame, 98 (1994), 59-79

[14] Warnatz J., Maas U., Dibble R.W.: Combustion, physical and chemical fundamentals, modelling and simulation, experiments, pollutant formation, 4th Ed. Springer, 2006

Received

November 2012 